\title{
.
}

\section{EL CUMPLIMIENTO DE LA NORMATIVA DE COMPETENCIA COMO VENTAJA COMPARATIVA DE LA EMPRESA}

Una política de «cumplimiento normativo» (compliance) es una herramienta mediante la cual una empresa muestra de manera interna y externa su compromiso de acatamiento, respeto y seguimiento de las distintas normativas que le afectan y adapta sus procedimientos y su operativa a tal fin. En el caso de la política de competencia, la propia empresa es responsable de la autoevaluación de sus conductas, con lo que ha desarrollar programas de cumplimiento normativo. La popularidad de estos programas de compliance en materia de competencia está en crecimiento por una mayor percepción de las ventajas que aporta el cumplimiento de la normativa y de los costes que supone el incumplimiento.

Palabras claves: derecho de la competencia, cumplimiento normativo, competitividad, ventaja comparativa.

Clasificación JEL: K14, K21, K42.

\section{Introducción}

Una política de «cumplimiento normativo» (compliance) es una herramienta mediante la cual una empresa muestra de manera interna y externa su compromiso de acatamiento, respeto y seguimiento de las distintas normativas que le afectan y adapta sus procedimientos y su

* Vocal Asesor de la Subdirección de Estudios e Informes. Departamento de Promoción de la Competencia de la CNMC.

Versión de diciembre de 2017.

Las opiniones expresadas en el presente artículo son exclusivamente del autor y no necesariamente coinciden con las de la CNMC. El autor desea agradecer las aportaciones de Diego Castro-Villacañas Pérez, Julia García-Royo Díaz, Antonio Maudes Gutiérrez y María Sobrino Ruiz.Los eventuales erroresuomisionesson, encualquiercaso, responsabilidad exclusiva del autor. operativa a tal fin (Lachnit, 2014). Entre estas regulaciones de obligado cumplimiento destacan aspectos de seguridad, salud pública, medioambiente y también la normativa de competencia.

La normativa de competencia pretende salvaguardar el libre juego de las fuerzas del mercado de oferta y demanda, de forma que las empresas compitan en pie de igualdad y los consumidores puedan acceder a los bienes y servicios en las condiciones más favorables. El sujeto pasivo de esta política en la Unión Europea (UE) es el «operador», concepto que no está definido en el Tratado de Funcionamiento de la Unión Europea (TFUE), pero que ha sido moldeado por la jurisprudencia del Tribunal $\triangle$ 
de Justicia de la Unión Europea (TJUE) como «toda entidad que ejerce una actividad económica, con independencia de su estatus jurídico y su forma de financiación». Se trata, por tanto, de una definición funcional, y cualquier entidad puede ser «operador» o no según la actividad afectada en cada caso. El concepto de «actividad económica» solo excluye de su alcance la provisión de bienes y servicios de acuerdo a principios no económicos como el ejercicio de la autoridad pública (como en el caso de la defensa, la seguridad, el control del tráfico y la vigilancia medioambiental) o la solidaridad (como en el caso de la Seguridad Social, la sanidad pública, algunas actividades de educación e investigación y las infraestructuras no destinadas a ser explotadas comercialmente).

Por tanto, la política de competencia afecta a la actuación de los «operadores» en el mercado y estos son en general responsables de informarse bien sobre la regulación aplicable y cumplirla. Pero, más allá de esta obligación de conocimiento y respeto de la normativa de competencia, la tesis de este artículo es que ese cumplimiento normativo es de hecho rentable para la propia empresa. Para ello puede ser recomendable disponer de una política de compliance para prevenir y corregir fuentes que supongan un riesgo de infracción de la legislación, lo que puede constituir una fuente de ventaja comparativa. A tales efectos, el artículo se estructura como sigue tras este primer apartado introductorio.

El segundo apartado describe, si bien de manera sucinta, los principales trazos de la normativa de competencia. El tercer apartado compara los costes y beneficios de cumplir (o no) dicha normativa. Tras este análisis se concluye que el cumplimiento aporta a la empresa más ventajas que perjuicios, con lo que el cuarto apartado recomienda el diseño de una política de cumplimiento normativo (compliance) para prevenir riesgos y corregir eventuales fuentes de vulneración de la legalidad. A partir de estas pautas generales de diseño, el quinto apartado apunta aspectos concretos y prácticos en materia de normativa de competencia y autoevaluación de conductas. El sexto y último apartado recoge las principales implicaciones y conclusiones.

\section{Breve repaso de la normativa de competencia}

La política de competencia es una facultad exclusiva de la Unión Europea (UE), donde los Estados miembros (EEMM) han cedido su soberanía para preservar un adecuado funcionamiento del mercado único. Así se asegura que no se distorsione el comercio entre EEMM ni la competencia entre sus empresas, de forma que los ciudadanos de la UE disfruten las ventajas que entraña la integración económica.

La Comisión Europea, como guardiana de la normativa comunitaria y en su condición de Autoridad de Competencia de la $\mathrm{UE}^{1}$, debe velar por estas cuestiones, destacando?:

- El artículo 101 del TFUE3 ${ }^{3}$ que prohíbe y declara nulos e incompatibles con el $D$

\footnotetext{
1 En los casos en que carezcan de relevancia comunitaria, la Comisión Europea deja la custodia de estas cuestiones a las Autoridades Nacionales de Competencia, en el caso de España, la Comisión Nacional de los Mercados y la Competencia (CNMC). De la misma manera que estas últimas pueden descargar sus funciones en autoridades subcentrales para casos sin relevancia nacional, como hace la CNMC, como Autoridad de Competencia española, con las autoridades de las CCAA.

2 Otra disposición relevante es el artículo 106 del TFUE, que establece que todas estas normas aplican indistintamente a las empresas públicas, a los monopolios con derechos exclusivos y a empresas encargadas de la gestión de servicios de interés económico general (SIEG), en la medida en que la aplicación de dichas normas no impida el cumplimiento de la misión específica atribuida a estas empresas.

3 El artículo 101 del TFUE se transpone al ordenamiento jurídico español con el artículo 1 de la Ley 15/2007, de 3 de julio, de Defensa de la Competencia (en adelante, LDC). Estas conductas también están afectadas por los artículos 4 a 6 de la LDC y por los artículos 1 a 3 del Reglamento de Defensa de la Competencia (RDC), aprobado por Real Decreto 261/2008, de 22 de febrero.
} 
mercado interior los acuerdos entre empresas o asociaciones de empresas y las prácticas concertadas que puedan afectar al comercio entre EEMM y que tengan por objeto o efecto impedir, restringir o falsear la competencia. Esto afecta, por ejemplo, a la fijación de precios u otras condiciones de la transacción, a la limitación de la producción, la inversión o el desarrollo tecnológico, al reparto de mercados, a la aplicación a terceros de condiciones desiguales para prestaciones equivalentes o a la subordinación de la celebración de contratos a la aceptación de prestaciones inconexas con el objeto de dichos contratos. Una conducta que no está explícitamente incluida en el artículo 101 pero que también se enmarca dentro de este ámbito es el intercambio privado de información entre empresas competidoras que afecte a información comercialmente sensible (como previsiones de precios, producción, calidades, costes, listas de clientes, etcétera) y reduzca la incertidumbre estratégica en el mercado. No obstante (en virtud del apartado 3 del artículo 101), se podrán permitir todas estas prácticas si mejoran la producción o la distribución de los productos o fomentan el progreso tecnológico, siempre que los consumidores obtengan un beneficio y las prácticas restrictivas sean indispensables para alcanzar estos objetivos y no se reduzca la competencia de manera sustancial.

- El artículo 102 del TFUE4, que prohíbe y declara incompatible con el mercado interior la explotación abusiva de una

4 El artículo 102 del TFUE se transpone al ordenamiento jurídico español con el artículo 2 de la LDC. Estas conductas también están afectadas por los artículos 4 a 6 de la LDC y por los artículos 1 a 3 del RDC. posición dominante en el mercado. Esto afecta, por ejemplo, a la imposición de precios u otras condiciones de la transacción, a la limitación de la producción o el desarrollo tecnológico en perjuicio de los consumidores, a la aplicación a terceros de condiciones desiguales para prestaciones equivalentes o a la subordinación de la celebración de contratos a la aceptación de prestaciones inconexas con el objeto de dichos contratos.

- El «Reglamento de Concentraciones» 5 , que establece que la Comisión Europea, como Autoridad de Competencia comunitaria, ha de examinar las operaciones de integración entre empresas cuando puedan suponer una reducción substancial de la competencia en el mercado, pudiendo prohibir dicha integración o someter su aprobación a la adopción de ciertos compromisos $^{6}$.

Las empresas que incumplan esa normativa pueden ser multadas por un importe de hasta el 10 por 100 de su volumen de negocios global $^{7}$ si violan los artículos 101 y 102 del TFUE (independientemente de que sea de manera negligente o deliberada) o si omiten el deber de notificar una concentración. Aparte, las propias resoluciones de las Autoridades de Competencia normalmente les otorgan la posibilidad de establecer nuevas multas o sanciones en un futuro si las empresas no $D$

5 Reglamento (CE) N.․ 139/2004 del Consejo, de 20 de enero de 2004, sobre el control de las concentraciones entre empresas. En materia de concentraciones, el ordenamiento jurídico español está contenido en los artículos 6 a 10 de la LDC y en los artículos 4 a 6 del RDC.

6 De las casi 7.000 operaciones de concentración notificadas a la Comisión Europea entre septiembre de 1990 y junio de 2017 solo 42 se han prohibido y 141 se han aprobado condicionadas a la adopción de determinados compromisos.

7 Los tribunales en España han tendido a rebajar las sanciones notablemente por debajo de ese umbral, que tomaban como un límite máximo sobre el que aplicar los factores atenuantes en respeto de principio de proporcionalidad (Pascual, 2015). 
cumplen determinados compromisos ${ }^{8}$ (tanto por violaciones de los artículos 101 y 102 del TFUE como por no aplicar los remedios a los que se condicionaba la aprobación de una operación de concentración).

Las multas pretenden tener una dimensión punitiva para la empresa infractora, pero también un rol disuasorio para minimizar el riesgo de que estas conductas se repitan en el futuro por parte de la misma empresa o de cualquier otra. Y, además de las multas, existen otros costes derivados del incumplimiento de la normativa de competencia que se desgranan en el apartado a continuación.

\section{Costes y beneficios del cumplimiento de la normativa de competencia}

Pese a la existencia de las antedichas sanciones ( $\mathrm{y}$ otros costes más amplios que analizaremos a continuación), la normativa de competencia es vulnerada de manera ocasional o frecuente por ciertas empresas. Una primera causa de incumplimiento puede ser el propio desconocimiento de este cuerpo legal y su complejidad $^{9}$ (Beaton-Wells y Parker, 2013).

Pero, más allá de que la falta de información pueda ser una explicación en ocasiones, es evidente que la mayoría de casos de incumplimiento se deben a que las empresas pueden considerarlo beneficioso por encima del valor esperado de la multa. Por un lado, el recurso a prácticas colusorias (como un cártel de

\footnotetext{
8 Otras disposiciones en materia de competencia son las relativas al control de ayudas públicas (artículos 107 y 108 del TFUE), que pueden resultar prohibidas en la medida en que distorsionen la competencia y el comercio entre Estados miembros. En este caso la responsabilidad recae en el Estado que concedió la ayuda, que debe restituir los fondos públicos, con lo que las empresas también resultan afectadas aunque sea indirectamente.

9 Aparte de otras explicaciones psicológicas más heterodoxas, como la arrogancia de ciertos directivos, las ansias de desobediencia o el alimento del propio ego por ser el líder de un cártel.
}

concertación de precios o de reparto del mercado) puede ser una estrategia óptima para las empresas (aunque muy perjudicial para el bienestar del consumidor y de la economía en general) en contextos donde hay pocos competidores, la interacción es continua, la demanda y la oferta son estables, el producto es homogéneo, el mercado es transparente, etcétera. Por otro lado, el abuso de posición de dominio (como la prohibición a proveedores/clientes de tratar con competidores) puede ser una estrategia rentable para desalentar la presencia de competidores en un mercado donde existan barreras de entrada. Estas ideas se han instalado en la cultura corporativa de muchas empresas, creando un pensamiento colectivo (groupthink) de que el incumplimiento de las normas de competencia es ventajoso para la empresa si no es detectado.

No obstante, la adopción unilateral o plurilateral de estas prácticas anticompetitivas puede ser rentable a corto plazo en una tesitura determinada, pero nada garantiza que siga siéndolo a largo plazo en todos los contextos. Por ejemplo, la eficacia de un cártel puede romperse por la salida de uno de los participantes. De hecho, una de las razones para abortar un acuerdo entre competidores podría ser precisamente beneficiarse de uno de los aspectos más destacados de la normativa de competencia como es la política de clemencia (leniency), bajo la cual se otorgan reducciones en la multa (que pueden llegar hasta el 100 por 100 para el primero en denunciar) a empresas que hayan participado en un cártel y lo abandonen para denunciarlo. La estabilidad de un cártel también puede verse amenazada por cambios en el sector, como una mayor competencia internacional o la aparición de nuevos entrantes. De la misma manera, una empresa con una posición de dominio aparentemente confortable $\triangleright$ 
puede verse afectada por una reducción súbita e inesperada de las barreras de entrada por revoluciones tecnológicas o una mayor apertura internacional.

Es decir, no está claro que la vulneración de la normativa de competencia siempre conlleve beneficios para la empresa infractora. Más aún, si tenemos en cuenta los costes del incumplimiento, que son de diversa índole (Office of Fair Trading, 2011, y Comisión Europea, 2012).

El primer impacto negativo, a la par que el más obvio e importante, es la satisfacción de las ya mencionadas multas. A ello se añade el gasto de recursos humanos y económicos que se dedican a responder a la investigación de las autoridades y a construir la defensa en el proceso judicial en lugar de destinarse a cuestiones ordinarias de la empresa, con el consiguiente perjuicio para la eficiencia y la productividad. $Y$ también supone un daño reputacional para la empresa (que afecta tanto a sus directivos como a sus trabajadores), con un perjuicio para su imagen de marca que podría conllevar la pérdida de clientes, proveedores, inversores e incluso trabajadores que pierdan identificación con la compañía.

Como se ha comentado, las multas pueden llegar al 10 por 100 de la cifra de negocios global de la compañía, aunque hay autores que estiman que deberían alcanzar el 150-200 por 100 de la cifra de negocios de la empresa en el mercado afectado para ser realmente disuasorias (Borrell et al., 2015). Pero ello supondría la quiebra de la empresa en la mayor parte de los casos, con lo que no es factible y de hecho puede ser lesivo de la competencia al expulsar a una empresa del mercado (Whelan, 2013). Por ello existen otras herramientas punitivas y disuasorias.

Las sanciones penales se consideran en cada vez más jurisdicciones (Borrell et al., 2015), tanto fuera de la UE (Estados Unidos, Canadá o Australia) como dentro (Reino Unido o Irlanda), aunque generalmente solo para los cárteles, por dos razones. Por un lado, porque estos tienen un mayor elemento probatorio en contraposición con otros casos, como el abuso de posición de dominio, que tienen un mayor grado de juicio económico. Por otro lado, porque los cárteles implican una práctica particularmente lesiva de la competencia ${ }^{10}$, con el consiguiente impacto negativo sobre el bienestar del consumidor y de la economía en general (Werden, 2009), especialmente en los denominados cárteles de «línea dura» (hard core cartels): fijación de precios, pacto de ofertas en licitaciones (bid rigging), reparto de mercados por clientes o limitación de producción, inversión o innovación tecnológica ${ }^{11}$.

España no es de los países que se ha subido a esta ola de «criminalización» de los cárteles, dado que las infracciones de competencia siguen la vía de la jurisdicción contenciosoadministrativa. No obstante, ciertas conductas «anticompetitivas» sí están tipificadas dentro del Código Penal. Se trata de los artículos 262, sobre las manipulaciones de precios y otras condiciones de concursos y subastas públicas; 281 , sobre restricciones en la producción de productos de primera necesidad y materias primas, y 284 , por la manipulación de precios respecto de la libre competencia empleando violencia, amenaza o engaño (Ramos y Cabrera, 2008, y Ventura et al., 2002). Los que realicen este tipo de conductas «anticompetitivas» $\square$

10 Una muestra de la consideración negativa hacia los cárteles en la legislación española es el hecho de que no se benefician (a tenor del artículo 2 del RDC) de excepciones de minimis (artículo 5 de la LDC y el artículo 1 del RDC) que permiten exonerar del cumplimiento de la normativa a conductas de escasa importancia. Es decir, estas conductas se persiguen independientemente de que su impacto en el mercado sea pequeño, casi por motivos educativos e higiénicos.

11 Estos cárteles se denominan así en contraposición con los cárteles de línea blanda (soft cartels), que se basan en una serie de prácticas, como el intercambio de información, donde caben más matices. 
se exponen a penas de prisión, aunque no por violar la normativa de competencia como tal.

El recurso a penas criminales es una cuestión controvertida no solo por sus implicaciones morales, sino también por las limitaciones prácticas que dificultan la demostración de una culpabilidad individual. Las Autoridades de Competencia solo podrían centrarse en un número muy limitado de casos en este ámbito por el importante desgaste que conllevarían (aparte de la exposición pública). Su falibilidad les obligaría a ser más cautas cuanto más duras fueran las penas, pues pueden cometer «errores tipo |» (over-enforcement, es decir, sancionar de manera injusta a empresas y personas que no deberían ser penalizadas) y «errores tipo II» (under-enforcement, es decir, no castigar a empresas y personas que sí deberían ser penalizadas, lo cual en cierta medida también es injusto para las empresas y personas que sí son sancionadas).

Pero el uso de la vía penal tiene respaldo teórico (Wils, 2005) y empírico (Borrell et al., 2015), pues aumenta la capacidad de disuasión en comparación con las multas a la empresa. $Y$ especialmente porque permite sortear los problemas derivados de la separación entre la propiedad por parte de los accionistas y el control por parte de los directivos. Los segundos pueden verse tentados por conductas cortoplacistas como los cárteles ${ }^{12}$, pero los perjudicados por una multa a la empresa son los accionistas, que no tienen un control directo sobre la misma, con lo que puede ser preferible una sanción penal al directivo responsable.

No obstante, para mantener la capacidad disuasoria dentro del dilema que supone la

\footnotetext{
12 Aunque a largo plazo no sean óptimas ni siquiera para la propia empresa por las razones comentadas anteriormente, como la entrada o salida de competidores o los cambios tecnológicos y de competencia internacional.
}

separación entre propiedad y control existen otras alternativas menos radicales dentro de la vía administrativa, sin recurrir al encausamiento penal. Una posibilidad es imponer multas pecuniarias a las personas físicas que integran los órganos directivos de las empresas infractoras $^{13}$. Esta opción, ya utilizada en el pasado (especialmente en la década de los noventa), está siendo integrada en algunas resoluciones recientes de la $\mathrm{CNMC}^{14}$ en función de la capacidad decisoria de los directivos, de sus facultades de organización y control, de sus responsabilidades y, especialmente, de su participación en el diseño y ejecución de la conducta infractora. También dentro de la vía administrativa está la prohibición de contratar con la Administración a empresas sancionadas con carácter firme por infracción grave en materia de falseamiento de la competencia ${ }^{15}$.

A esto hay que añadir otros elementos disuasorios, en este caso más relacionados con la aplicación privada. Los acuerdos restrictivos de la competencia son nulos de pleno derecho (en virtud del artículo 101.2 del TFUE), por lo que las partes implicadas no pueden exigir su ejecución. Por otro lado, los terceros afectados por una infracción de las normas de competencia pueden solicitar el resarcimiento de los daños y perjuicios ante un tribunal ${ }^{16}$, cuestión que se ha reforzado recientemente en la $\triangleright$

\footnotetext{
13 Estas multas están contempladas en el artículo 63.2 de la LDC y pueden llegar a 60.000 euros.

14 Animada, de hecho, por la Sentencia del Tribunal Supremo de 29 de enero de 2015, que citaba esta opción como una manera de potenciar las herramientas disuasorias ante la reducción de las multas.

15 De acuerdo con el artículo 71.1.b de la Ley 9/2017, de 8 de noviembre, de Contratos del Sector Público, por la que se transponen al ordenamiento jurídico español las Directivas del Parlamento Europeo y del Consejo 2014/23/UE y 2014/24/UE, de 26 de febrero de 2014 (está ley entrará en vigor el 9 de marzo de 2018, si bien hasta entonces estará en vigor el texto refundido de la Ley de Contratos del Sector Público aprobado por Real Decreto Legislativo 3/2011, de 14 de noviembre, cuyo artículo 60.1.b tiene una redacción análoga a estos efectos).

16 Sobre esta cuestión también entra la susodicha Sentencia del Tribunal Supremo de 29 de enero de 2015, como una tendencia internacional para potenciar las herramientas disuasorias.
} 
UE mediante la aprobación de la denominada Directiva de Daños ${ }^{17}$ (Comisión Europea, 2015).

En definitiva, el respeto de la normativa de competencia entraña ventajas para la empresa, por lo que ella misma ha de estar interesada en formular una política de cumplimiento normativo (compliance) que prevenga y corrija eventuales riesgos. A detallar la forma de construir esta política y sus ventajas asociadas se dedica precisamente el próximo apartado.

\section{La construcción de una política de cumplimiento normativo}

Como se ha comentado en la introducción, la adopción de una política de cumplimiento normativo es una herramienta por la que una empresa muestra su compromiso de respeto de la legalidad y adapta para ello su funcionamiento. Normalmente, los programas de compliance se incluyen en un código de conducta más amplio dentro de la estrategia de gobierno corporativo.

En el caso de la política de competencia, se ha constatado cómo su cumplimiento entraña ventajas para la propia empresa, por lo que adoptar un programa exitoso de compliance supondrá aprovechar esos beneficios. Pero es que, además, una política de cumplimiento normativo entraña per se otros aspectos positivos en ciertas áreas que se detallan a continuación.

17 Directiva 2014/104/UE del Parlamento Europeo y del Consejo, de 26 de noviembre de 2014, relativa a determinadas normas por las que se rigen las acciones por daños en virtud del Derecho nacional, por infracciones del Derecho de la competencia de los Estados miembros y de la Unión Europea. Esta directiva se ha transpuesto al ordenamiento jurídico español en virtud del Real Decreto-ley 9/2017, de 26 de mayo, por el que se transponen directivas de la Unión Europea en los ámbitos financiero, mercantil y sanitario, y sobre el desplazamiento de trabajadores.
La primera ventaja sería la posible rebaja de las multas por vulneración de la normativa de competencia en el caso de que la empresa disponga de una política de cumplimiento normativo. Esta opción ya se considera en EEUU18, Reino Unido, Francia e Italia, aunque en todos los casos se insiste en que no basta con la mera existencia de un programa de compliance, sino que ha de ser una verdadera política integrada que muestre un grado de compromiso máximo por parte de la empresa (JalabertDoury et al., 2015).

La Comisión Europea, como Autoridad de Competencia comunitaria, también anima a las empresas a adoptar una política de cumplimiento normativo para prevenir y corregir riesgos (Comisión Europea, 2012). Sin embargo, no lo considera un factor atenuante (ni agravante) para eventuales multas, pues el mejor premio a un programa exitoso de compliance es que la empresa no se vea inmersa en un procedimiento sancionador ${ }^{19}$.

La CNMC (y su antecesora, la CNC), como Autoridad de Competencia en España, ha tendido a mantener una visión análoga a la de la Comisión Europea ${ }^{20}$, señalando que un programa de cumplimiento no puede ser considerado en general un atenuante, dado que la existencia de una infracción ya muestra las deficiencias del programa y no es signo de un compromiso genuino de la empresa. Aunque también se ha admitido la posibilidad de que la implantación de un programa de cumplimiento exitoso tras la apertura de un expediente puede moderar sanciones, ya sea en la $D$

18 Las «Directrices para la imposición de penas» (Sentencing Guidelines) permiten utilizar los programas de compliance como atenuante en general, aunque esta opción no ha sido muy utilizada en competencia (Thépot, 2015), con alguna excepción reciente (Volkov, 2016).

19 Es una línea coincidente con la sentencia del TJUE en el asunto C-501/11 Schindler Holding y otros / Comisión Europea.

20 Véase, por ejemplo, la Resolución de la CNMC, de 23 de julio de 2015, en el Expediente S/0482/13 «Fabricantes de automóviles». 
propia resolución o en la fase de vigilancia de su cumplimiento ${ }^{21}$. Y, en general, nunca se ha descartado la posibilidad de que sea un factor atenuante de cada caso en función de las circunstancias de cada caso ${ }^{22}$.

Los debates en España sobre la posibilidad de tomar los programas de cumplimiento como un atenuante de las sanciones de competencia se han alimentado tras la reciente reforma del Código Penal, que atenúa o exime de la responsabilidad penal a las personas jurídicas ante ciertos delitos cometidos por sus empleados si contaban con adecuados modelos de organización y gestión para la prevención del riesgo, vigilancia y control ${ }^{23}$. La Circular 1/2016 de la Fiscalía General del Estado desarrolla ciertas interpretaciones sobre el diseño de estos modelos para el cumplimiento normativo, que deben conducir a una verdadera cultura ética corporativa de respeto a la ley a partir de diversas herramientas ${ }^{24}$ : compromiso al más alto nivel y dotación de medios, difusión interna, protocolos de comunicación, evaluación, etcétera. Aunque esta reforma del Código Penal no afecta a las sanciones por vulneración de la normativa de competencia (pues éstas no se corresponden con la vía penal), esta idea puede acabar inspirando la potestad sancionadora de la Administración ${ }^{25}$ (Jalabert-Doury et al., 2015).

Donde los programas de cumplimiento sí podrán actuar como claro atenuante es en la ya mencionada prohibición de contratar con

\footnotetext{
21 Véase la Resolución de la CNMC, de 6 de septiembre de 2016, en el Expediente S/DC/0544/14 «Mudanzas Internacionales».

22 Aprovechando la condición de «numerus apertus» del artículo 64.1.g) de la LDC, que permite considerar cualesquiera circunstancias atenuantes o agravantes en la determinación del importe de las sanciones.

23 Se trata de una nueva redacción de su artículo 31 bis dada por la Ley Orgánica 1/2015, de 30 de marzo, por la que se modifica la Ley Orgánica 10/1995, de 23 de noviembre, del Código Penal.

24 Esta circular confiere especial valor a las herramientas que permiten el descubrimiento de los delitos por la propia corporación.

25 Véase de nuevo la Resolución de la CNMC, de 6 de septiembre de 2016, en el Expediente S/DC/0544/14 «Mudanzas Internacionales».
}

la Administración a empresas sancionadas con carácter firme por infracción grave en materia de falseamiento de la competencia ${ }^{26}$. Esa prohibición se levantará cuando concurran ciertas causas $^{27}$, como la adopción de medidas técnicas, organizativas y de personal apropiadas ${ }^{28}$ para evitar la comisión de futuras infracciones, incluyendo también acogerse al ya mencionado programa de clemencia.

Pero más allá de estas ventajas en forma de una eventual rebaja de multas, los programas de compliance aportan otra serie de ventajas más intangibles pero igualmente relevantes para consolidarse como una ventaja comparativa de la empresa. Por un lado, se trata de una herramienta que aporta un mayor conocimiento interno para mitigar riesgos y asegurar una rápida actuación para su corrección, rapidez que, por ejemplo, puede ser muy útil para beneficiarse plenamente del programa de clemencia (al ser el primero en denunciar un cártel y optar a una reducción de la multa de hasta el 100 por 100).

Por otro lado, es una fuente de mejora de la reputación externa que puede reforzar la imagen de la empresa para clientes, proveedores y la sociedad en general. También para inversores y accionistas, pues al fin y al cabo los programas de cumplimiento son una manera de solventar el problema ya mencionado de la separación entre propiedad (en manos de accionistas) y control (en manos de los gestores directivos). La implantación de programas de cumplimiento actúa como un mecanismo de control interno de la empresa (que se complementa bien con la imposición de penas o $\square$

\footnotetext{
26 De acuerdo con el antedicho artículo 71.1.b de la Ley 9/2017, de 8 de noviembre, de Contratos del Sector Público.

27 De acuerdo con el artículo 72.5 de la Ley 9/2017, de 8 de noviembre, de Contratos del Sector Público, que también menciona otras causas del levantamiento de la prohibición como el pago de las multas.

28 Lo que se entiende como una referencia implícita a los programas de cumplimiento.
} 
sanciones a personas físicas como mecanismo de control externo (Borrell et al., 2015).

Para aprovechar todas estas ventajas tangibles e intangibles los programas de cumplimiento normativo han de cumplir una serie de requisitos de forma, exigidos por las Autoridades de Competencia $^{29}$ o por las legislaciones penales ${ }^{30}$ que lo toman como atenuante o eximente, y de fondo, para asegurar su efectividad en la práctica. Estos requisitos formales y de fondo van de hecho en la misma línea.

En el caso de la normativa de competencia, el diseño de una política de compliance no debe ser meramente «reactiva» (Requejo, 2008). Es decir, no ha de consistir únicamente en la corrección ocasional de desviaciones de la normativa que se puedan producir a corto plazo ante la amenaza de multas u otras sanciones. Al contrario, esta política debe ser proactiva y estratégica, creando una cultura de cumplimiento que permee toda a la empresa, de forma que se prevengan los riesgos de vulneración de la normativa (Lachnit, 2014). Esto solo es posible bajo el convencimiento de que, más allá de las imposiciones legales, el cumplimiento de la normativa de competencia generará mejoras en el funcionamiento y la reputación de la empresa, que incidirán positivamente en su competitividad (Riley y Sokol, 2015).

Una política adecuada de compliance debe tener estos pilares (Europe Economics, 2008; Comisión Europea, 2012; CMA, 2014; ICC, 2015):

1. Compromiso visible y duradero al más alto nivel. El elemento envolvente a la

\footnotetext{
29 Véanse las susodichas «Directrices para la imposición de penas» (Sentencing Guidelines) en el caso de los Estados Unidos o los documentos publicados por las Autoridades de Competencia de Francia (Document cadre sur les programmes de conformité), Reino Unido (OFT's guidance as to the appropriate amount of a penalty) e Italia (Linee Guida in materia di sanzioni).

30 Tal y como enfatiza la Circular $1 / 2016$ de la Fiscalía General del Estado.
}

política de compliance es la implicación al más alto nivel en todos los elementos que se describirán a continuación, desde el diseño hasta el seguimiento y la evaluación. Para ello se debe optar por una estructura organizativa coherente, diseñando eventualmente una unidad bajo un alto directivo, de forma que se señalice el grado de prioridad de estos objetivos (Murphy, 2015). Esta unidad también debe ser responsable de establecer los protocolos de comunicación en el caso de riesgo de cumplimiento que se describirán más adelante. Los recursos destinados al área de compliance deben ser proporcionales a los factores de riesgo que se describen a continuación y al propio tamaño de la empresa (que puede ser de hecho otro factor de riesgo si está asociado a una posición de dominio). En ocasiones será difícil encontrar los recursos necesarios para formar una unidad separada encargada del cumplimiento normativo, por lo que se pueden insertar las funciones dentro de otro departamento (como el de asesoría jurídica y legal o el de control interno).

2. Detección de los riesgos de incumplimiento. Este primer paso consistirá en el análisis de diversos factores ${ }^{31}$ :

- El sector de actividad. Existen actividades más propensas a plantear problemas de competencia y que por tanto son susceptibles de un escrutinio más serio por autoridades de competencia. Los ejemplos más $\triangleright$

\footnotetext{
31 Aparte de los mencionados más abajo, también hay otros factores que pueden dar lugar a conductas lesivas de la competencia, como la transparencia, el crecimiento estable del mercado, la escasez de innovación o la interacción de las mismas empresas en más de un mercado (Ivaldi et al, 2003).
} 
habituales son mercados con barreras de entrada y salida, donde existen pocos participantes y reducida creación y destrucción de empresas. Suelen ser también sectores donde hay dificultades para encontrar mano de obra cualificada, por lo que la movilidad de trabajadores entre empresas competidoras puede crear un clima de colusión.

- El contexto del mercado. Aparte de los rasgos estructurales del sector, la empresa debe tener en cuenta el contexto de mercado en el que se mueve en cada momento. El análisis de las cuotas de mercado resulta fundamental, ya que una asimetría muy grande puede informar de una eventual posición de dominio. Pero al mismo tiempo una excesiva simetría y estabilidad de las cuotas de mercado puede alertar de un clima proclive a la colusión y al reparto de clientes entre pocos participantes. Por ello suele argumentarse que, en general, habrá menos riesgos de vulneraciones de la competencia cuanto más diferentes sean las empresas en términos de costes, capacidades, calidades y cuotas de mercado (salvo que exista una empresa dominante).

- La interacción con los competidores, tanto en lo que respecta a la frecuencia como al rango o nivel. Esta interacción puede producirse en las relaciones comerciales del día a día o en momentos ocasionales, como ferias o reuniones de las asociaciones profesionales o sectoriales. Cuanto más frecuente y a más alto nivel sea la interacción, mayores son los riesgos de vulneración de la normativa de competencia.

- El tipo de empresa. La adopción de un programa de compliance es más necesaria en empresas donde los empleados y las unidades sean difíciles de supervisar, especialmente cuando el poder para decidir ciertas variables claves (como precios o producción) está descentralizado. Un ejemplo muy claro de todo lo anterior son las empresas multinacionales, que además se enfrentan al reto de satisfacer múltiples normativas diferentes en materia de competencia, con lo que su programa de cumplimiento debe intentar adaptarse a la jurisdicción más exigente.

3. El contenido de la estrategia. Se debe describir la normativa de competencia, explicitar las repercusiones de su incumplimiento y dar unas orientaciones al personal y a las unidades de la empresa para prevenirlo. Entre esas directrices deben incluirse unas «líneas rojas» de conductas a evitar por su carácter claramente lesivo de la competencia (Comisión Europea, 2012; ICC, 2015):

- En la interacción horizontal con competidores, no incurrir en acuerdos de fijación de precios o reparto de mercados ni en la comunicación de información comercialmente sensible ${ }^{32}$ (como futuras estrategias de precios, producción y comercialización).

- En la interacción vertical con proveedores o clientes, no establecer $D$

32 Por ejemplo, es más grave el intercambio de información individualizada y presente o futura (de más interés comercial) que el de información agregada y pasada (como las estadísticas). Asimismo, es más preocupante una comunicación de manera activa y secreta que una comunicación de modo más pasivo y en foros públicos. 
restricciones como precios de reventa o limitaciones geográficas.

- Las empresas con posición de dominio (normalmente aquéllas con una cuota superior al 40 por 100 del mercado relevante, aunque también puede haber escrutinio para umbrales inferiores) deben tener una cautela especial y abstenerse de ciertas prácticas, como la negativa a proveer o la discriminación injustificada entre clientes.

4. Difusión interna de la estrategia, incluyendo formación continua y sensibilización. Una política de compliance debe ir mucho más allá de los documentos (que contengan los códigos de conducta o las estrategias), influyendo en procedimientos y permeando en la cultura de la organización. La comunicación de la estrategia debe combinar diversos formatos para asegurar su efectividad, desde la publicación de un manual público accesible interna y externamente (por ejemplo, en la web de la entidad) hasta la organización de actividades de formación interna. Se debe abarcar a todo el personal y a toda la estructura organizativa (incluyendo las distintas áreas geográficas), especialmente a aquellas unidades donde los factores de riesgo sean mayores (por ejemplo, por una mayor interacción con los competidores). El personal con capacidad de decisión requiere una atención especial, no solo los altos directivos, sino también los rangos intermedios, pues estos últimos pueden tender a tomar/tolerar ciertas decisiones para agradar a sus superiores y/o beneficiarse de esquemas de remuneración que priman a toda costa la rentabilidad a corto plazo sin valorar cómo se están alcanzando esos objetivos (Riley y Sokol, 2015).

5. Comprobación del cumplimiento. La empresa debe realizar autoevaluaciones del grado de compliance, ya sea mediante cuestionarios internos con una checklist (ICC, 2015) para comprobar si las diferentes unidades y su personal están cumpliendo con las directrices, ya sea mediante auditorías externas (que pueden incluso «simular» inspecciones de competencia).

6. Introducción de incentivos. Se pueden introducir premios económicos o sanciones monetarias disciplinarias a las unidades y al personal en función del grado de cumplimiento detectado.

7. Protocolos claros de comunicación interna y externa. Si un empleado o un directivo sospecha o descubre riesgos de incumplimiento de las normas de competencia, deben existir protocolos claros de actuación que aseguren una respuesta ágil de la empresa. Es por ello que es aconsejable dotar a la empresa de una unidad de compliance dirigida por un directivo para que la toma de decisiones a alto nivel sea lo más rápida posible. Si el incumplimiento de la normativa de competencia aún no se ha producido y simplemente se trata de un factor de riesgo, es importante que la empresa lo afronte lo más rápidamente posible. Si el incumplimiento ya se ha manifestado, se debe proceder a la comunicación con las autoridades de competencia (que habilitan cauces que respetan la adecuada confidencialidad), también a la mayor brevedad posible, en estos dos casos:

- Las empresas pueden informar a una autoridad de competencia de $\triangleright$ 
cualquier sospecha de infracción de la que tengan conocimiento o eventualmente interponer una demanda de haber sido víctima de conductas anticompetitivas por parte de otras empresas. La rapidez en este caso también es importante, porque cuanto antes disponga la autoridad de competencia de la información, antes podrá adoptar una determinada decisión que eventualmente sancione a la empresa incumplidora y declare esos actos nulos (en beneficio de la víctima denunciante), habilitándola incluso para reclamar el resarcimiento de daños.

- Las empresas que reconozcan haber estado implicadas en una infracción de las normas de competencia pueden obtener una dispensa o reducción de las multas. De nuevo la rapidez es crucial porque, por ejemplo, las empresas que antes denuncien un cártel acogiéndose a un programa de clemencia se beneficiarán de mayores rebajas en las sanciones.

8. Evaluación. La política de compliance debe ser evaluada y mejorada en el caso de detectarse limitaciones, debiéndose recurrir tanto al control interno como a la auditoría externa. El éxito de un programa de este tipo no debe medirse por los medios dispuestos, sino en términos de su efectividad para eliminar cualquier tipo de riesgo de conductas anticompetitivas.

Estas son las grandes líneas maestras de una política de cumplimiento normativo, aunque su aplicación día a día genera complejidades y retos que nos disponemos a detallar a continuación.

\section{La aplicación cotidiana del cumplimiento de la normativa de competencia}

La importancia del cumplimiento de la normativa de competencia se incrementó de manera especial tras la aprobación del denominado Reglamento de Procedimiento ${ }^{33}$ en 2003. Anteriormente a dicho reglamento existía un régimen de autorización singular ex ante de las conductas de las empresas a cargo de las Autoridades de Competencia, que debían autorizar las conductas una a una, con los consiguientes costes y trámites administrativos ${ }^{34}$.

Actualmente, tras la aprobación de este reglamento, los acuerdos se benefician a priori de una exención legal, aunque las Autoridades de Competencia pueden actuar ex post en el caso de detectar vulneraciones de la normativa (Requejo, 2008). Esto incrementa la responsabilidad de las empresas en el conocimiento ${ }^{35}$ y el cumplimiento de la normativa, debiendo proceder a una autoevaluación de si su conducta respeta o no la normativa de competencia (CNC, 2009).

Esta «autoevaluación privada» de los operadores respecto a sus propias conductas puede estructurarse en tres pasos (Requejo, 2008). En primer lugar, la empresa debe plantearse si su conducta es o tiene riesgos de ser anticompetitiva. Una empresa que disponga de una cuota elevada en su mercado relevante tiene una responsabilidad especial, pues puede incurrir en abusos de posición de dominio $\triangleright$

\footnotetext{
33 Reglamento (CE) N. 1/2003 del Consejo, de 16 de diciembre de 2002 , relativo a la aplicación de las normas sobre competencia previstas en los artículos 81 y 82 del Tratado (los artículos 81 y 82 del Tratado corresponden a los actuales artículos 101 y 102 del TFUE).

34 Aparte de restar flexibilidad a las Autoridades de Competencia a la hora de sancionar ex post una conducta que estaba perjudicando la competencia pero que en principio había sido avalada ex ante.

35 Incluyendo el seguimiento de la jurisprudencia y la interpretación de la normas de acuerdo a la misma.
} 
(que vulneren el artículo 102 del TFUE), aparte de la concertación de prácticas (violando el artículo 101 del TFUE), como cualquier empresa.

Si la respuesta a la primera pregunta es negativa, no haría falta seguir el análisis, pero si es positiva y hay riesgos de conducta anticompetitiva, entonces la empresa se ha de preguntar si se beneficia de excepciones como «reglamentos de exención por categorías» (que afectan a ciertos ámbitos como la transferencia de tecnología o los acuerdos de especialización o distribución), excepciones sectoriales (como las existentes para agricultura, seguros, automóviles, servicios postales, transporte o comunicaciones electrónicas) o excepciones por conductas «de minimis» de escasa importancia ${ }^{36}$, cuestión que puede beneficiar a las pymes en ciertos casos, aunque éstas no estén exentas del cumplimiento de la normativa ${ }^{37}$. Si la empresa no se beneficia de estas excepciones, entonces deberá demostrar las eficiencias inherentes a su conducta, siempre que los consumidores se aprovechen de las mismas y la competencia no se reduzca de manera sustancial (en virtud del artículo 101.3 del TFUE).

Si la respuesta a la segunda pregunta es positiva y la empresa se beneficia de excepciones, entonces sí podrá continuar con su conducta, pero si la respuesta a esa segunda pregunta es negativa, entonces hay riesgos claros de vulneración de la normativa de competencia. En estos casos, a la empresa solo le queda cesar en su conducta o solicitar el acceso al programa de clemencia (en las prácticas concertadas contempladas en el artículo 101 del TFUE)

\footnotetext{
36 Véase la «Comunicación de minimis» (Comunicación 2014/C/291 relativa a los acuerdos de menor importancia que no restringen la competencia de forma sensible en el sentido del artículo 101, apartado 1, del Tratado de Funcionamiento de la Unión Europea) y el artículo 5 de la LDC y el artículo 1 del RDC.

37 Especialmente en el caso de los cárteles, en los que no suelen existir excepciones de minimis por su carácter particularmente lesivo de la competencia, tal y como señala el artículo 2 del RDC.
}

para cooperar plenamente con la Autoridad de Competencia en su investigación (a la par que se abandona la conducta) para optar a una rebaja de la sanción.

En definitiva, se trata de cuestiones complejas que implican que las Autoridades de Competencia deben fomentar el conocimiento y el cumplimiento de la normativa, como proponemos en las conclusiones.

\section{Conclusiones}

Tal y como se ha comentado a lo largo del artículo, el cumplimiento de la normativa de competencia y en particular la adopción de un programa de compliance aportan ventajas para las propias empresas. Por eso podría pensarse que las autoridades no tienen la necesidad de apoyar estas políticas, pues los operadores las adoptarán de manera autónoma.

Sin embargo, en ocasiones las empresas pueden no conocer la normativa o guiarse por creencias equivocadas, como el hecho de que el incumplimiento siempre será rentable. Ante estos problemas, las Autoridades de Competencia han de involucrarse, a través de diversas herramientas (información, seminarios y jornadas, formación, comunicación, etcétera), en labores de promoción (advocacy) sobre la normativa de competencia y sus beneficios para el bienestar del consumidor, la eficiencia y la innovación y también para las propias empresas. Esto llevará a menos casos de incumplimiento por parte de las propias empresas y también a más denuncias por parte de otros operadores y de los propios consumidores.

Más controvertido es obviamente el debate de si las Autoridades de Competencia han de considerar una política de compliance como un atenuante en la imposición de $D$ 
sanciones $^{38}$. Otra solución más gradual sería introducir como remedio en las resoluciones la obligación para las empresas sancionadas de adoptar un programa de cumplimiento de la normativa de competencia ${ }^{39}$. En realidad, no son propuestas tan independientes, pues, una vez se considerara que un programa de cumplimiento es un remedio apropiado para modificar la conducta de una empresa, un paso lógico posterior serían plantearse considerarlo como atenuante en casos ulteriores, obviamente siempre que el programa cuente con los aspectos formales y de fondo comentados anteriormente y no por su mera existencia.

En cualquier caso, es obvio que las autoridades deben promover estos programas (ya sea con la labor de promoción o con otros incentivos, más blandos o más tangibles), pues los beneficios del cumplimiento de la normativa de competencia no quedan solo en el ámbito de la empresa, sino que pueden generar externalidades positivas en forma de una cultura de cumplimiento que logre consolidar los beneficios de la competencia para los consumidores y para el interés general.

\section{Bibliografía}

[1] BEATON-WELLS, C. y PARKER, C. (2013). «Justifying Criminal Sanctions for Cartel Conduct: A Hard Case». Journal of Antitrust Enforcement, 2013, vol. 1, n.․ 1, pp. 198-219.

[2] BORRELL, J.R.; JIMÉNEZ, J.L. y LUNA, Y.E. (2015). «Crímenes y castigos en la lucha contra los cárteles». Economía Industrial, n.우 398, pp. 129-144.

\footnotetext{
38 Posibilidad que permite el artículo 64.1.g) de la LDC en su condición de numerus apertus.

39 Opción también abierta en el artículo 53.1.b). Por ejemplo, en el marco del Expediente S/DC/0522/14 «Thyssenkrupp», la Autoridad de Competencia española impuso como condición que la empresa informase de manera apropiada a sus trabajadores de los compromisos adquiridos, lo cual podría ir en la línea de adoptar un programa de compliance.
}

[3] COMISIÓN EUROPEA (2012). La importancia de cumplir. Qué pueden hacer las compañías para respetar mejor las normas de competencia de la UE.

[4] COMISIÓN EUROPEA (2015). «The Damages Directive - Towards more effective enforcement of the EU competition rules». Competition Policy Brief, 2015, n. .1 (January).

[5] COMISIÓN NACIONAL DE LA COMPETENCIA (2009). Guía para asociaciones empresariales.

[6] COMPETITION \& MARKETS AUTHORITY (2014). Competition law risk: A short guide.

[7] EUROPE ECONOMICS (2008). Etat des lieux et perspectives des programmes de conformité. Une étude réalisée pour le Conseil de la concurrence.

[8] INTERNATIONAL CHAMBER OF COMMERCE (2015). Why complying with competition law is good for your business. Practical tools for smaller businesses to improve compliance. ICC Commission on Competition.

[9] IVALDI, M.; JULLIEN, B.; REY, P.; SEABRIGHT, P. y TIROLE, J. (2003). «The Economics of Tacit Collusion». IDEI Working Paper, n.ㅇ 186.

[10] JALABERT-DOURY, N.; HARRISON, D. y SCHMIDT, J.P. (2015). «Enforcers' Consideration of Compliance Programs in Europe: A Long and Winding -but Increasingly Interesting- Road». CPI Antitrust Chronicle, 2015, vol. 6 (June).

[11] LACHNIT, E. (2014). «Compliance Programmes in Competition Law: Improving the Approach of Competition Authorities». Utrecht Law Review, vol. 10, n. -5 .

[12] MURPHY, J. (2015). «Agency Assessments of Compliance Programs». CPI Antitrust Chronicle, 2015, vol. 6 (June).

[13] OFFICE OF FAIR TRADING (2011). «How your business can achieve compliance with competition law». Guidance, OFT 1341.

[14] PASCUAL, C. (2015). «El sistema de cálculo de sanciones por prácticas anticompetitivas a debate». Nada es gratis (3 de diciembre).

[15] RAMOS, A. y CABRERA, E. (2008). «El programa español de clemencia. Análisis y cuestiones prácticas». Revista de Derecho de la Competencia y la Distribución, n. .2 .

[16] REQUEJO, A. (2008). «La autoevaluación de las conductas: ¿misión imposible?». Revista de Derecho de la Competencia y la Distribución, n.․․ 1 . 
[17] RILEY, A. y SOKOL, D.D. (2015). «Rethinking compliance». Journal of Antitrust Enforcement, 2015, vol. 3, n. 1, pp. 31-57.

[18] THÉPOT, F. (2015). «Antitrust v. Anti-Corruption Policy Approaches to Compliance: Why Such A Gap?». CPI Antitrust Chronicle, 2015, June (2).

[19] VENTURA, M.; PARET, J.M. y FERNÁNDEZVICIÉN, C. (2002). «¿Pueden ir a prisión los directivos españoles por la comisión de conductas anticompetitivas llevadas a cabo por su empresa?». Gaceta Jurídica de la Unión

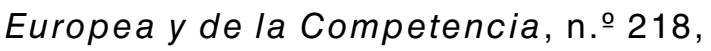
pp. 35-51.
[20] VOLKOV, M. (2016). «The Often Ignored Importance of Antitrust Compliance (Part I of II)». Corruption, Crime and Compliance (2 de agosto).

[21] WERDEN, G.J. (2009). «Sanctioning cartel activity: Let the punishment fit the crime». European Competition Journal, pp. 19-35.

[22] WHELAN, P. (2013). «Cartel Criminalization and the Challenge of Moral Wrongfulness". Oxford Journal of Legal Studies, vol. 33, n. 3 , pp. 535-561.

[23] WILS, W.P.J. (2005). «Is Criminalization of EU Competition Law the Answer?». World Competition, vol. 28, n.․․ 2, pp. 117-159. 


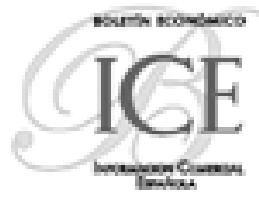

TÍTULOS PUBLICADOS EN 2017
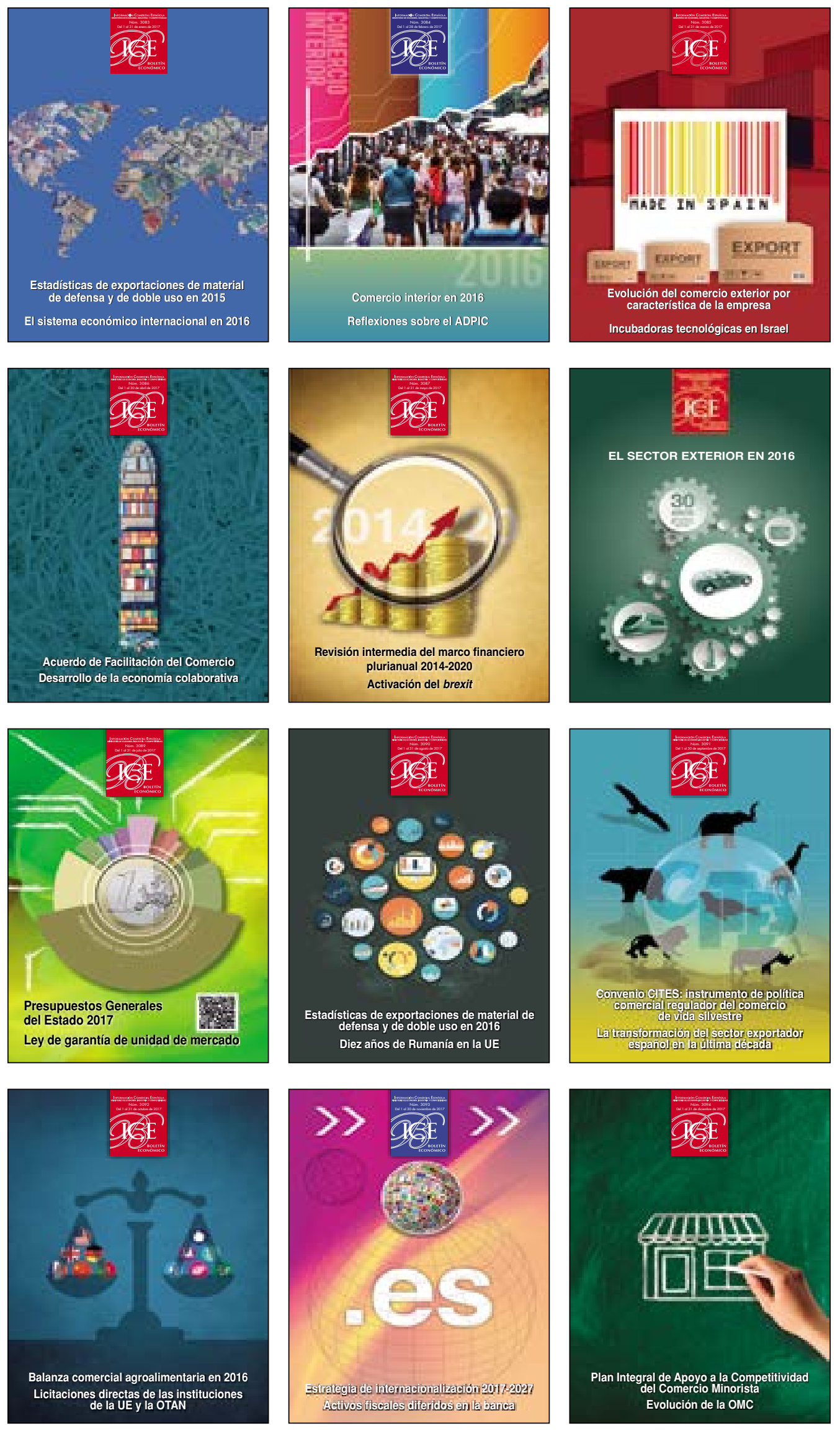

Página web: www.revistasice.com

Librería virtual, suscripción y venta: www.mineco.gob.es 